\title{
Vinte anos de
}

fundamentação freireana

na produção do Grupo de Pesquisa Comunicação e Educação da Intercom

Ana Luisa Zaniboni Gomes

Doutora pela ECA-USP, integra o Grupo de Pesquisa Mediações Educomunicativas, do CNPq, vicecoordenadora do Grupo de Pesquisa Comunicação e Educaşão da Intercom e diretora da Oboré.

E-mail: analuisagomes@obore.com

Rose Mara Pinheiro

Professora do Programa de Pós-Graduação em Comunicação e do curso de Jornalismo da UFMS. Coordenadora dos Grupos de Pesquisa Comunicação e Educação da Intercom e da UFMS (CNPq).

E-mail: rose.pinheiro@ufms.br

Resumo: $\bigcirc$ objetivo deste artigo é destacar a presença de Paulo Freire como fundamentação teórica na produção científica do Grupo de Pesquisa Comunicação e Educação, ligado à Sociedade Brasileira de Estudos Interdisciplinares da Comunicação, entre os anos de 2001 e 2020. Para isso, foram analisados os 847 artigos apresentados em congressos nacionais neste período. Como resultado, a pesquisa aponta que em $41 \%$ dos textos há referências ao educador brasileiro - principalmente às obras Extensão ou comunicação?, Pedagogia do oprimido e Pedagogia da autonomia -, especialmente a conceitos como educação bancária, aprendizagem significativa, formação crítica, assim como reflexões sobre interação professor-aluno, diálogo e fundamentos da prática docente.

Palavras-chave: educomunicação; comunicação e educação; diálogo; Paulo Freire; Intercom.
Abstract: This article aims to highlight the presence of Paulo Freire as a theoretical foundation in the scientific production of the Communication and Education Research Group, linked to the Brazilian Society for Interdisciplinary Studies in Communication, between 2001 and 2020. To that end, we analysed the 847 articles presented at national congresses during this period. As a result, the survey shows that $41 \%$ of the texts reference the Brazilian educator - especially the works Extension or Communication? (1969), Pedagogy of the Oppressed (1974) and Pedagogy of Freedom (1996) -, especially concepts such as banking education, meaningful learning, critical education, and reflections on teacher-student interaction, dialogue, and fundamentals of teaching practice.

Keywords: edu-communication; communication and education; dialogue; Paulo Freire; Intercom.

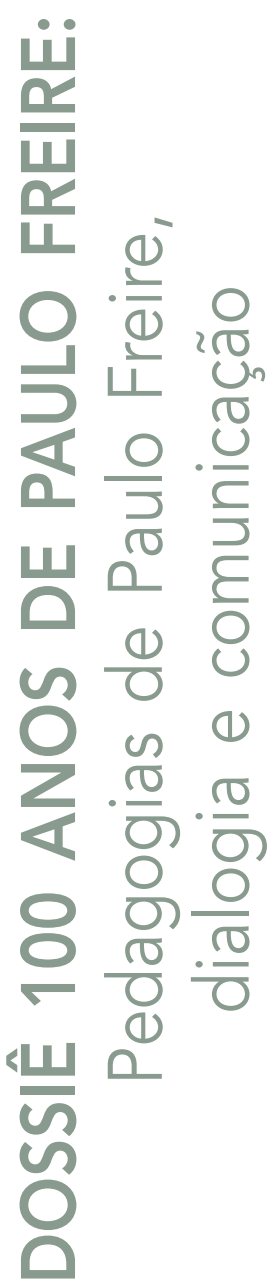

Recebido: 13/06/2021

Aprovado: 18/10/2021 


\section{CONSIDERAÇÕES INICIAIS}

Reconhecer a importância do pensamento de Paulo Freire nos estudos do campo da Comunicação é compreender a comunicação como um ato de natureza educativa e, portanto, política: a educação e a comunicação, enquanto práticas libertadoras, carregam em si a potência da autonomia dos sujeitos e da transformação social. Este conceito está relacionado, em essência, ao diálogo e à conversa, e se cumpre na relação com o outro. Está também relacionado a meios e mensagens, a produtos e a tecnologias.

Tal perspectiva está presente no Brasil desde a década de 1970 e, mais de 50 anos depois, ainda é atual, ganhando contornos de resistência e esperança para superar a maior crise sanitária do planeta, a pandemia da covid-19, e enfrentar uma grande onda de desinformação e polarização política virtual jamais vista na história humana.

Este é o contexto em que este artigo se ancora para qualificar a importância da obra de Freire na produção acadêmica do Grupo de Pesquisa (GP) Comunicação e Educação, ligado à Sociedade Brasileira de Estudos Interdisciplinares da Comunicação (Intercom). Desde a sua criação, em 2001, o Grupo contabiliza um total de 847 artigos científicos nas mais diversas áreas, reunindo pesquisadores de todas as regiões do país.

A partir dos Anais dos congressos nacionais da Intercom do período entre 2001 e 2020, disponíveis no portal oficial da entidade, foram analisados todos os 847 artigos apresentados nesse GP. Foi utilizada análise quali-quantitativa para investigar cada um dos textos, com ajuda do software MaxQDA ${ }^{1}$, em sua versão gratuita.

$\mathrm{Na}$ investigação, cada um dos artigos foi aberto para que a palavra Freire fosse buscada. Ela foi encontrada em 345 dos textos publicados e disponíveis no site da Intercom. Após o levantamento, com a utilização do programa Excel, foram abertas abas para cada ano e extraídos dados referentes a bibliografia, título, nome do autor ou autora e citações de cada artigo. Dessa forma, foi possível reunir as menções e as principais obras utilizadas na fundamentação teórica de cada texto.

De 2001 a 2020, em média, 41\% da produção do GP fez referência ou menção a Paulo Freire, e os anos que alcançaram o maior percentual foram 2015, com 52\%, e 2013, com 51\%. Nesses anos, os congressos foram realizados, respectivamente, no Rio de Janeiro, com o tema "Comunicação e Cidade Espetáculo"; e em Manaus, com "Comunicação em tempo de redes sociais: afetos, emoções, subjetividades" (Gráfico 1).

Já a Tabela 1 identifica os Anais dos congressos das duas últimas décadas, as diversas coordenações do GP nesse período, quantifica as produções científicas e, nelas, o percentual de citações de Freire, ano a ano.

A incidência de Paulo Freire é notada especialmente nos textos que se dedicam a discutir escrita e leitura, letramento, autonomia e educação para os meios, e que se assentam em teorias da cultura para discorrer sobre práticas de conhecimento e de liberdade, do engajamento como ação transformadora e destacar o compromisso dos educadores na luta contra o analfabetismo e a desigualdade social. Tais estudos estão categorizados como Comunicação;

1. Disponível em: https:// www.maxqda.com/. Acesso em: 10 jun. 2021. 
Comunicação e Educação; Ecossistemas comunicacionais e educativos; Educação; Educomídia; Educomunicação; Formação nos vários níveis de escolarização; Formação continuada; Formação docente; Interfaces comunicacionais; Leitura e recepção crítica dos meios; Linguagens da mídia; Linguagens em espaços educativos; Mediações e suas implicações nos processos formativos formais, informais e não formais; Mediações tecnológicas; Mídia-educação; Novas tecnologias, Recursos educativos e Relações da educação com processos comunicativos.

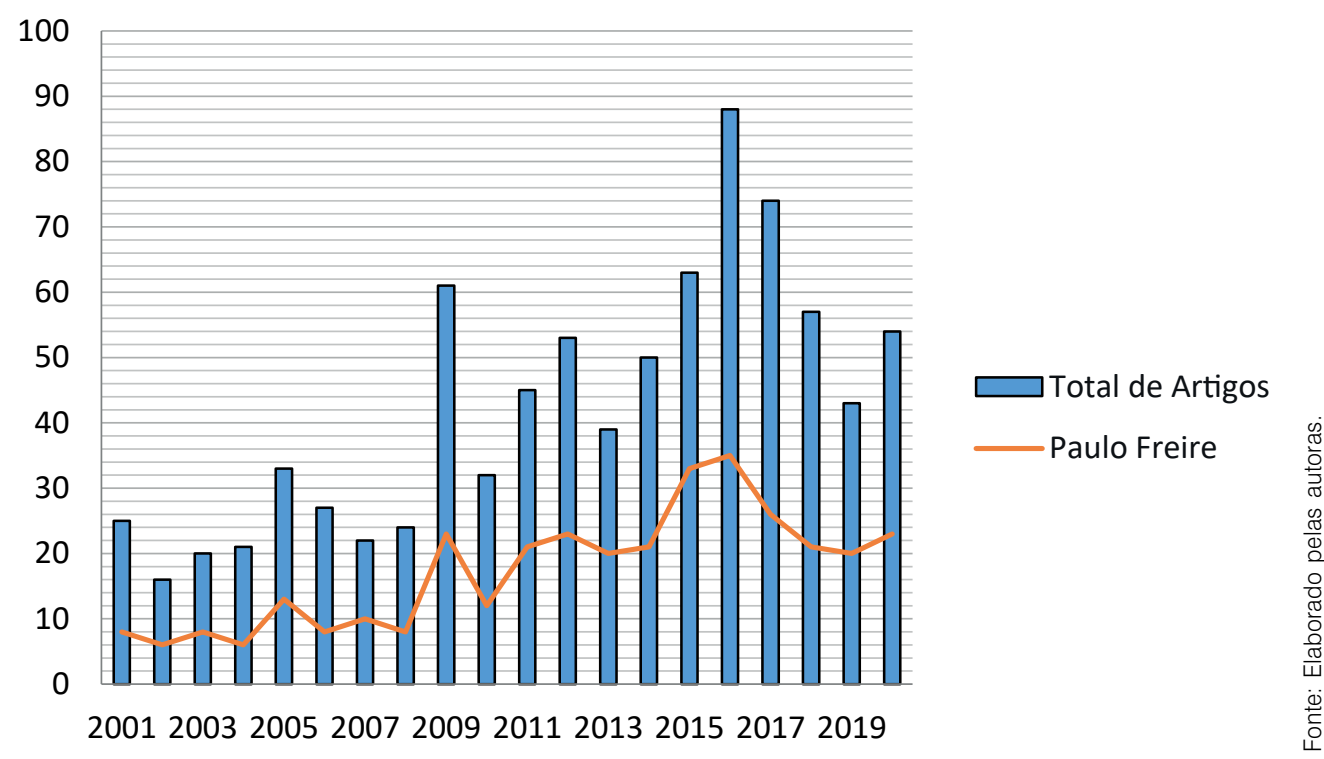

Gráfico 1: Comparação entre o total de textos e as citações a Paulo Freire localizadas nos artigos acadêmicos apresentados no GP Comunicação e Educação entre 2001 e 2020

Tabela 1: Total de produções acadêmicas apresentadas no GP Comunicação e Educação entre 2001 e 2020 e total de artigos que referenciaram alguma obra de Paulo Freire

\begin{tabular}{|l|l|l|c|c|c|} 
ANAIS & \multicolumn{1}{|c|}{ LOCAL } & \multicolumn{1}{|c|}{ COORDENAÇÃO } & ARTIGOS & $\begin{array}{c}\text { ARTIGOS } \\
\text { COM } \\
\text { CITAÇÕES }\end{array}$ & $\%$ \\
\hline 2020 & Salvador/BA & Rose Mara Pinheiro & 54 & 23 & $43 \%$ \\
\hline 2019 & Belém/PA & Ana Luisa Gomes & 43 & 20 & $47 \%$ \\
\hline 2018 & Joinville/SC & Ana Luisa Gomes & 57 & 21 & $37 \%$ \\
\hline 2017 & Curitiba/PR & Eliana Nagamini & 74 & 26 & $35 \%$ \\
\hline 2016 & São Paulo/SP & Eliana Nagamini & 88 & 35 & $40 \%$ \\
\hline 2015 & Rio de Janeiro/RJ & Eliana Nagamini & 63 & 33 & $52 \%$ \\
\hline 2014 & Foz do Iguaçu/PR & Eliana Nagamini & 50 & 21 & $42 \%$ \\
\hline 2013 & Manaus/AM & Ademilde Sartori & 39 & 20 & $51 \%$ \\
\hline 2012 & Fortaleza/CE & Ademilde Sartori & 53 & 23 & $43 \%$ \\
\hline 2011 & Recife/PE & Ademilde Sartori & 45 & 21 & $47 \%$ \\
\hline
\end{tabular}


Tabela 1: Continuação

\begin{tabular}{|c|l|l|c|c|c|}
\hline ANAIS & \multicolumn{1}{|c|}{ LOCAL } & \multicolumn{1}{|c|}{ COORDENAÇÃO } & ARTIGOS & $\begin{array}{c}\text { ARTIGOS } \\
\text { COM } \\
\text { CITAÇÕES }\end{array}$ & $\%$ \\
\hline 2010 & Caxias do Sul/RS & Ademilde Sartori & 32 & 12 & $38 \%$ \\
\hline 2009 & Curitiba/PR & Belarmino Guimarães Costa & 61 & 23 & $38 \%$ \\
\hline 2008 & Natal/RN & Belarmino Guimarães Costa & 24 & 8 & $38 \%$ \\
\hline 2007 & Santos/SP & Belarmino Guimarães Costa & 22 & 10 & $45 \%$ \\
\hline 2006 & Brasília/DF & Belarmino Guimarães Costa & 27 & 8 & $30 \%$ \\
\hline 2005 & Rio de Janeiro/RJ & Maria Aparecida Baccega & 33 & 13 & $39 \%$ \\
\hline 2004 & Porto Alegre/RS & Maria Aparecida Baccega & 21 & 6 & $29 \%$ \\
\hline 2003 & Belo Horizonte/MG & Maria Aparecida Baccega & 20 & 8 & $40 \%$ \\
\hline 2002 & Salvador/BA & Adilson Citelli & 16 & 6 & $38 \%$ \\
\hline 2001 & Campo Grande/MS & Adilson Citelli & 25 & 8 & $32 \%$ \\
\hline TOTAL & & & 847 & 345 & $41 \%$ \\
\hline
\end{tabular}

Percebe-se, a partir da leitura dessa produção intelectual de duas décadas, o interesse dos pesquisadores no resgate da prática dialógica e do protagonismo do aluno, detentor de repertórios próprios, criativos e dinâmicos. Nota-se também a busca constante do poder emancipador dos processos educativos e comunicativos como caminho para a construção coletiva de uma nova realidade via junção de saberes, troca de experiências e vivência com o outro.

Vale destacar que, criado formalmente em 2001, o GP aglutina cerca de 80 pesquisadores, majoritariamente doutores, com ampla trajetória na pós-graduação das áreas da Comunicação e da Educação, da Pedagogia, das Licenciaturas e da Educomunicação, além de estudiosos de áreas como Música, Saúde e Humanidades. Esses pesquisadores, oriundos de territórios educativos formais, informais ou não formais, dedicam-se a refletir sobre temas próprios do vínculo entre Comunicação e Educação, e grande parte das discussões ali mantidas são as reconfigurações do mundo contemporâneo, em que cada vez mais os dispositivos formativos e educacionais são tangidos e embalados pelo universo da comunicação e das tecnologias. Transitam também por questões focadas no processo do ensino-aprendizagem mediado pelas tecnologias, com ênfase na comunicação entendida como diálogo, com o objetivo utópico de transformação do indivíduo, da sociedade e do mundo em que vivemos ${ }^{2}$.

\section{O LEGADO DE PAULO FREIRE NO GP COMUNICAÇÃO E EDUCAÇÃO}

Pioneiro na inter-relação Comunicação e Educação na América Latina, o pensamento do patrono da Educação Brasileira constitui uma das principais bases das diversas nomenclaturas que materializam os estudos da área.

2. GOMES, Ana Luisa Zaniboni; NAGAMINI, Eliana; PINHEIRO, Rose Mara. Grupo de Pesquisa Comunicação e Educação da Intercom: quem somos, onde estamos, o que estudamos e quais horizontes nos desafiam. In: CONGRESSO BRASILEIRO DECIÊNCIASDAW COMUNICAÇÃO, 41., 2018, Joinville. Anais [...]. Joinville: Intercom, 2018., p. 3. 


\section{comunicação \& educação • Ano XXVI • número 2 • jul/dez 2021}

Os conceitos preconizados pelo educador e filósofo iluminam, desde a década de 1960, o caráter dialógico dos processos comunicacionais ao reafirmar a concepção da "educação para os meios" como atividade inerente aos programas de alfabetização e de educação popular.

Na tradição anglo-saxônica encontramos a Media Literacy, Media Education, Digital Literacy in Education e Education in Media Literacy; na França, Competénce Mediatique e Éducation aux Médias; na Itália, Educazione ai Media; na América espanhola e Espanha, Educación en Medios e Educación para la Comunicación; e no Brasil: Educomídia, Pedagogia da Comunicação, Educação Midiática, Comunicação e Educação, Literacia Digital, Educomunicação ${ }^{3}$.

Nesse aspecto, é importante lembrar não só a repercussão internacional da metodologia de alfabetização de adultos concebida por Freire, mas também suas reflexões sobre o papel da ciência e da educação no processo de conscientização dos indivíduos. São postulados nos quais se ancoram milhares de estudos, por todo o mundo, defendendo a educação como um compromisso social com a transformação da sociedade por meio de ações ativas e solidárias.

A título de exemplificação, recuperamos, no Quadro 1, citações significativas e recorrentes sobre Freire localizadas em 10 artigos pesquisados a fim de delimitarmos os contextos nos quais esses estudos navegam.

3. CITELLI, Adilson. Comunicação e educação: dinâmicas midiáticas e cenários escolares. Ilhéus: Editus, 2021, p. 13

4. CRUZ, Dulce Márcia. Educação a distância por videoconferência: como facilitar a adoção da inovação tecnológica e preparar os professores? In: CONGRESSO BRASILEIRO DE CIÊNCIAS DA COMUNICAÇÃO, 24., 2001, Campo Grande. Anais [...]. Campo Grande: Intercom, 2001.

5. TOSTA, Sandra Pereira. Tecnologias digitais na educação: estudo de caso em escolas da rede pública em Minas Gerais. In: CONGRESSO BRASILEIRO DE CIÊNCIASDA COMUNICACÃO 25. 2002, Salvador. Anais [...]. Salvador: Intercom, 2002

6. GAIA, Rossana Viana. Notícias na escola: possibilidades de leituras críticas. In: CONGRESSO BRASILEIRO DE CIÊNCIAS DA COMUNICAÇÃO, 25., 2002, Salvador. Anais [...] Salvador: Intercom, 2002.

\section{Quadro 1: Citações referenciando obras de Freire com tema do artigo e autoria}

\begin{tabular}{|l|l|}
\multicolumn{1}{|c|}{ Citação } & $\begin{array}{l}\text { Obra referenciada, tema } \\
\text { do artigo e autoria }\end{array}$ \\
\hline $\begin{array}{l}\text { "Se o professor não for preparado para responder a essa } \\
\text { sensação de estranhamento e desconforto, o risco de que a aula } \\
\text { tecnológica reproduza a educação bancária definida por Paulo } \\
\text { Freire (1988) é bastante grande" }\end{array}$ & $\begin{array}{l}\text { Referência àra } \\
\text { Pedagogia do } \\
\text { oprimido em artigo } \\
\text { sobre preparação de } \\
\text { professores para uso } \\
\text { de videoconferência na } \\
\text { educação a distância". }\end{array}$ \\
\hline $\begin{array}{l}\text { "Deste modo, sem ou com pouca familiaridade em ter os } \\
\text { meios massivos como mediadores nos processos de aquisição } \\
\text { de conhecimento, teria a escola rompido com o paradigma da } \\
\text { extensão enraizado e hegemônico nas práticas educacionais no país, } \\
\text { para adotar um paradigma dialógico ou de comunicação, conforme } \\
\text { propunha Freire (1976) já nos anos 60 do século passado?" }\end{array}$ & $\begin{array}{l}\text { Referência à obra } \\
\text { Extensão ou ounicação? em artigo } \\
\text { sobre as tecnologias } \\
\text { digitais na escola pública }\end{array}$ \\
\hline $\begin{array}{l}\text { "Para Freire (2000, p. 110), a única forma de não 'tropeçar na } \\
\text { compreensão dos fatos' é justamente evitar estar em frente da } \\
\text { TV em estado de completo relaxamento. [...] Ele alerta que as } \\
\text { ideologias são veiculadas de forma muito sutil pelos meios de } \\
\text { comunicação, exigindo dos que se propõem fazer uma leitura } \\
\text { crítica deles o exercício permanente da curiosidade. Em sua } \\
\text { opinião, é importante exercitar a crítica diante da mídia, uma vez } \\
\text { que esta tenta estabelecer uma verdade única. Ainda ele observa } \\
\text { que, ao repetir o que se divulgou em determinado jornal, muitos } \\
\text { de nós ficamos 'quase absolutamente possuídos pela verdade } \\
\text { sonora e coloridamente proclamada'". }\end{array}$ & $\begin{array}{l}\text { Referência à obra } \\
\text { Pedagogia da autonomia } \\
\text { em artigo sobre leituras } \\
\text { críticas em sala de aulab. }\end{array}$ \\
\end{tabular}

Continua... 


\section{Quadro 1: Continuação}

\begin{tabular}{|c|c|}
\hline Citação & $\begin{array}{l}\text { Obra referenciada, tema } \\
\text { do artigo e autoria }\end{array}$ \\
\hline $\begin{array}{l}\text { "Paulo Freire, em Pedagogia do oprimido, já defendia o } \\
\text { princípio de que a tessitura das relações sociais é mediada } \\
\text { pela comunicação. Para ele, refletir sobre os meios de } \\
\text { comunicação social é uma exigência para desenvolver técnicas } \\
\text { de aprendizagem. Quanto mais intensa for a comunicação, } \\
\text { maior será a interação e mais livres serão as pessoas envolvidas. } \\
\text { Freire acredita que "quanto mais cedo comece o diálogo, } \\
\text { mais revolução será [...]. Porque em uma sociedade que nega } \\
\text { o diálogo por meio da dominação política e econômica será } \\
\text { mais difícil acreditar na prática da educação dialógica ou da } \\
\text { pedagogia da comunicação". }\end{array}$ & $\begin{array}{l}\text { Referência à obra } \\
\text { Pedagogia do oprimido } \\
\text { em artigo sobre } \\
\text { representações e } \\
\text { significados de natureza } \\
\text { e sociedade em rádios na } \\
\text { Amazônia?. }\end{array}$ \\
\hline $\begin{array}{l}\text { "'O trabalho educativo realizado no projeto consiste exatamente } \\
\text { na utilização da Pedagogia Libertadora de Paulo Freire para a } \\
\text { conscientização dos alunos, através da realização de oficinas } \\
\text { pedagógicas. Durante as aulas, a comunicação se dá de forma } \\
\text { dialógica, fugindo do ensino tradicional onde o professor } \\
\text { simplesmente 'despeja' os conteúdos e aos alunos cabe apenas o } \\
\text { papel de meros ouvintes'. Freire (2003, p. 19) dedica um capítulo de } \\
\text { seu livro Educação e mudança sobre o compromisso do profissional } \\
\text { com a sociedade e vale destacar um trecho: 'O compromisso, } \\
\text { próprio da existência humana, só existe no engajamento com } \\
\text { a realidade, de cujas "águas" os homens verdadeiramente } \\
\text { comprometidos ficam "molhados", ensopados. Ao experienciá-lo, } \\
\text { num ato que necessariamente é corajoso, decidido e consciente, os } \\
\text { homens já não se dizem neutros. A neutralidade frente ao mundo, } \\
\text { frente ao histórico, frente aos valores, reflete apenas o medo que se } \\
\text { tem de revelar o compromisso". }\end{array}$ & $\begin{array}{l}\text { Referência à obra } \\
\text { Educação e mudança } \\
\text { em artigo sobre } \\
\text { a importância da } \\
\text { comunicação e do } \\
\text { exercício de cidadania } \\
\text { para mudar a realidade } \\
\text { da escola pública }{ }^{8} \text {. }\end{array}$ \\
\hline $\begin{array}{l}\text { "Mas, para a escola ser transformadora, precisa estar aberta ao } \\
\text { diálogo, a construção de um conhecimento problematizado e } \\
\text { precisa ampliar os espaços de comunicação, já que 'educação é } \\
\text { comunicação, é diálogo, na medida em que não é transferência } \\
\text { de saber, mas um encontro de sujeitos interlocutores que buscam } \\
\text { a significação dos significados'". }\end{array}$ & $\begin{array}{l}\text { Referência à obra } \\
\text { Extensão ou } \\
\text { comunicação? em relato } \\
\text { de experiência sobre } \\
\text { comunicação educativa } \\
\text { em uma rádio-escola9 }\end{array}$ \\
\hline $\begin{array}{l}\text { "O pedagogo brasileiro Paulo Freire (2002), considerado um dos } \\
\text { pensadores que mais aproximou a educação da comunicação, } \\
\text { deixou claro que a comunicação é fundamental para o processo } \\
\text { educativo, cabendo ao professor o papel de mediador e não } \\
\text { de um disciplinador que impõe idéias e estabelece modelos de } \\
\text { comportamento. Para ele, o diálogo deve ser constante no processo } \\
\text { de ensino e de aprendizagem, em que ser dialógico é 'vivenciar } \\
\text { o diálogo [...] é não invadir, é não manipular, é não sloganizar. Ser } \\
\text { dialógico é empenhar-se na transformação constante da realidade. } \\
\text { Esta é a razão pela qual, sendo o diálogo o conteúdo da forma de } \\
\text { ser própria à existência humana, está excluído de toda relação na } \\
\text { qual alguns homens sejam transformados em 'seres para outro' por } \\
\text { homens que são falsos 'seres para si'". }\end{array}$ & $\begin{array}{l}\text { Referência à obra } \\
\text { Extensão ou } \\
\text { comunicação? em } \\
\text { artigo sobre diferenças } \\
\text { e aproximações da } \\
\text { Interface Comunicação e } \\
\text { Educação em Congressos } \\
\text { Científicos }^{10}\end{array}$ \\
\hline $\begin{array}{l}\text { "'A leitura do mundo precede a leitura da palavra, daí que a } \\
\text { posterior leitura desta não possa prescindir da continuidade da } \\
\text { leitura daquele. Linguagem e realidade se prendem dinamicamente. } \\
\text { A compreensão do texto a ser alcançado por sua leitura crítica } \\
\text { implica a percepção das relações entre o texto e o contexto'". }\end{array}$ & $\begin{array}{l}\text { Referência à obra } \\
\text { A importância do ato de } \\
\text { ler em artigo sobre a sala } \\
\text { de leitura como espaço } \\
\text { de mediação }{ }^{11}\end{array}$ \\
\hline
\end{tabular}

7. CAMARGO, Cynthia Sociedade e natureza nas ondas do rádio na Amazônia: representações e significados. In: CONGRESSO BRASILEIRO DE CIÊNCIAS DA COMUNICAÇÃO, 29. 2006, Brasília, DF. Anais [...] Brasília, DF: Intercom, 2006

8. DELIBERADOR, Luzia Ya mashita. A importância da comunicação e do exercício de cidadania para mudar a realidade de uma escola pública. In: CONGRESSO BRASILEIRO DE CIÊNCIAS DA COMUNICAÇÃO, 30. 2007, Santos. Anais [...]. Santos: Intercom, 2007.

9. ARAÚJO, Alessandra Oliveira. A rádio-escola como uma experiência de comunicação educativa. In: CONGRESSO BRASILEIRO DE CIÊNCIAS DA COMUNICAČ̃O, 31 . 2008, Natal. Anais [...]. Natal: Intercom, 2008.

10. TOMITA, Iris; DALLA COSTA, Rosa Maria. A interface comunicação e educação em congressos científicos: diferenças aproximações. In: CON GRESSO BRASILEIRO DE CIÊNCIASDA COMUNICACÃO 34. 2011. Recife. Anais […]. Recife: Intercom, 2011.

11. ANDRADE Rogério Pelizzari de. Da leitura dos media à leitura dos livros: a sala de leitura como espaço de mediação. In: CONGRESSO BRASILEIRO DE CIÊNCIAS DA COMUNICAÇÃO, 35. 2012, Fortaleza. Anais [...] Fortaleza: Intercom, 2012. 
comunicação \& educação • Ano XXVI • número 2 • jul/dez 2021

12 ASSIS, Leandro Marlon Barbosa; FARBIARZ, Alexandre. Prática docente e as mídias digitais: o cotidiano de uma escola pública na região metropolitana do Rio de Janeiro. In: CONGRESSO BRASILEIRO DE CIÊNCIAS DA COMUNICAÇÃO, 41., 2018, Joinville. Anais [...]. Joinville: Intercom, 2018.

13 ACCIOLY, Denise Cortez da Silva. Educação para o século XXI: ler e interpretar as mídias dentro da escola. In: CONGRESSO BRASI LEIRO DE CIÊNCIAS DA COMUNICAÇÃO, 43., 2020, Salvador. Anais [...]. Salvador: Intercom, 2020.

14 ASSIS, Leandro Marlon Barbosa; FARBIARZ, Alexandre. Prática docente.. Op. cit.; CRUZ, Dulce Márcia. Educação a distância.. Op. cit.; TOMITA, Iris; DALLA COSTA, Rosa Maria. A interface... Op. cit.; TOSTA, Sandra Pereira. Tecnologias... Op. cit.

15 ACCIOLY, Denise Cortez da Silva. Educação.. Op. cit:; ARAÚJO, Alessandra Oliveira. A rádio-escola... Op. cit.; CAMARGO, Cynthia. Sociedade... Op. cit.; DELIBERADOR, Luzia Yamashita. A importância da comunicação do exercício de cidadania para mudar a realidade de uma escola pública. In: CONGRESSO BRASILEIRO DECIÊNCIASDACOMUNICAÇÃO, 30., 2007, Santos. Anais [...]. Santos: Intercom, 2007; GAIA, Rossana Viana. Notícias... Op. cit.

16 ACCIOLY, Denise Cortez da Silva. Educação.. Op. cit.; ANDRADE Rogério Pelizzari de Da leitura.. Op. cit.; ARAÚJO, Alessandra Oliveira. A rádio-escola... Op. cit.; ASSIS, Leandro Marlon Barbosa; FARBIARZ, Alexandre. Prática docente... Op. cit.; CAMARGO, Cynthia. Sociedade. Op. cit.; CRUZ, Dulce Márcia. Educação... Op. cit. DELIBERADOR, Luzia Yamashita. A importância.. Op. cit.; GAIA, Rossana Viana. Notícias... Op. cit.; TOMITA, Iris; DALLA COSTA, Rosa Maria. A interface. Op. cit.; TOSTA, Sandar Pereira. Tecnologias...Op. cit.

\section{Quadro 1: Continuação}

\begin{tabular}{|l|l|}
\multicolumn{1}{|c|}{ Citação } & $\begin{array}{l}\text { Obra referenciada, tema } \\
\text { do artigo e autoria }\end{array}$ \\
\hline $\begin{array}{l}\text { "Portanto, pensar a utilização da tecnologia, em especial as } \\
\text { mídias, requer a Educação e a Comunicação caminhando juntas } \\
\text { aos conceitos de Paulo Freire [...] para tomarmos posse do } \\
\text { conhecimento e nos tornarmos agentes ativos na sociedade". }\end{array}$ & $\begin{array}{l}\text { Referência às obras } \\
\text { Educação como prática } \\
\text { da liberdade e Extensão } \\
\text { ou comunicação? em } \\
\text { artigo sobre prática } \\
\text { docente e mídias digitais }{ }^{12}\end{array}$ \\
\hline $\begin{array}{l}\text { "'O mundo encurta, o tempo se dilui: o ontem vira agora; o } \\
\text { amanhã já está feito. Tudo muito rápido. Debater o que se diz e e } \\
\text { o que se mostra e como se mostra na televisão me parece algo } \\
\text { cada vez mais importante".". }\end{array}$ & $\begin{array}{l}\text { Referência à obra } \\
\text { Pedagogia da autonomia } \\
\text { em artigo sobre ler e } \\
\text { interpretar mídias na } \\
\text { escola no século XXI }\end{array}$ \\
\hline
\end{tabular}

Fonte: elaborado pelas autoras.

Os artigos selecionados (Quadro 1) foram produzidos em diferentes momentos de vida do GP; neles, os autores mencionam ao menos uma obra de Paulo Freire como embasamento de suas reflexões temáticas. Em comum, os textos destacam cenários e contextos ligados ao papel do educador - que cada vez mais exige uma dimensão de mediador do conhecimento e não de um disciplinador que impõe ideias e estabelece modelos de comportamento ${ }^{14}$.

Referem-se também a práticas pedagógicas em sala de aula, discutindo sobretudo a relação dialógica entre o professor e o aluno no processo de ensino-aprendizagem - já que, no entendimento de Freire, o diálogo é o elemento que costura as relações sociais ${ }^{15}$.

Outro tema muito presente nos textos é a questão do uso de tecnologias, em especial as mídias, na escola, o que, para os autores, requer constante formação e atualização do corpo docente a fim de que a técnica em si seja usada para ativar conhecimentos e compreensão crítica da sociedade atual. Nesse aspecto, destacam-se reflexões sobre leituras e abordagens críticas em sala de aula - como a importância de olhar e compreender o mundo e suas relações, pois, para Freire, o compromisso com a transformação, próprio da existência humana, só existe no engajamento com a realidade. Em outras palavras, a compreensão a ser alcançada pela leitura crítica dos textos implica a percepção das relações entre o texto e o contexto, ou seja, a realidade do mundo ${ }^{16}$.

\section{AS OBRAS MAIS REFERENCIADAS DE PAULO FREIRE}

A obra Extensão ou comunicação? ${ }^{17}$ é a mais citada por autores deste GP nas duas últimas décadas, sobretudo por embasar análises críticas sobre a falta de rompimento da escola com o paradigma da extensão enraizado e hegemônico nas práticas educacionais no país.

Títulos como Pedagogia da autonomia; Pedagogia do oprimido; Educação como prática da liberdade, Educação e mudança e A importância do ato de ler estão entre as seis obras mais citadas (Gráfico 2). 


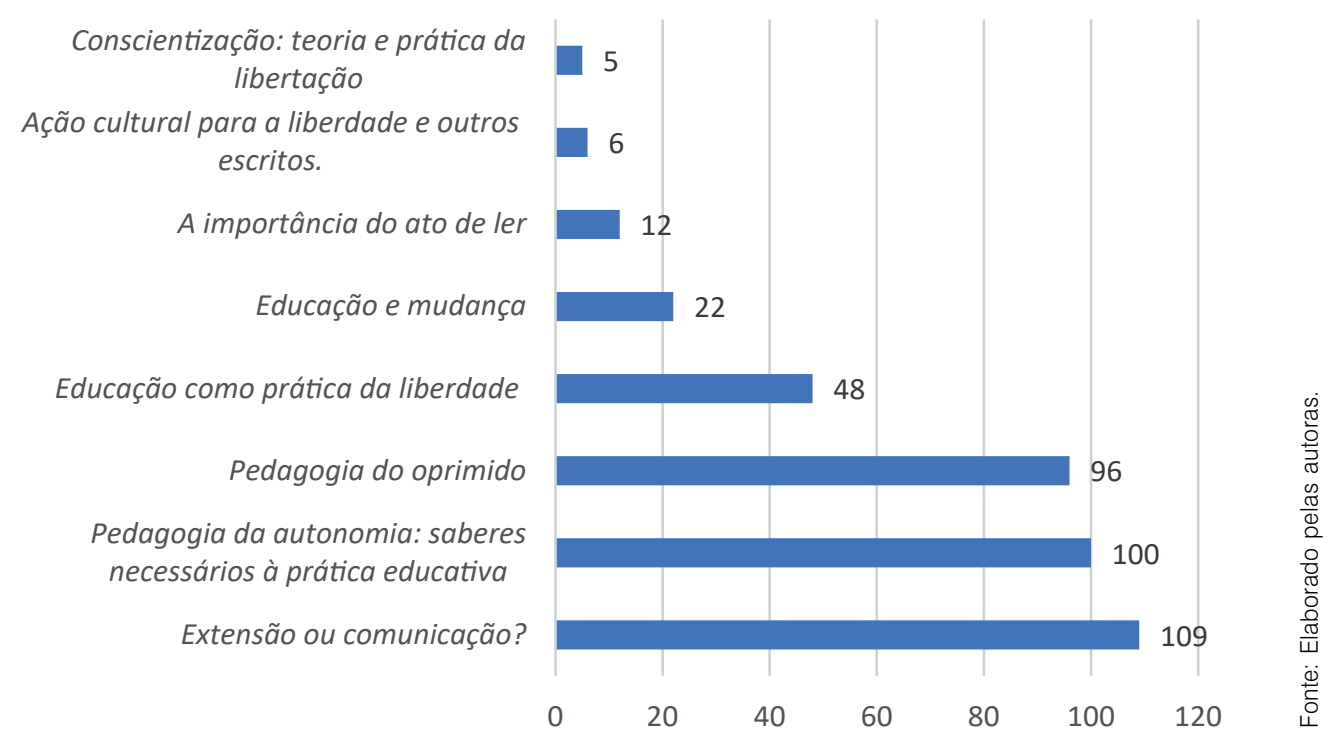

Gráfico 2: Obras de Paulo Freire mais citadas nos artigos acadêmicos apresentados no GP Comunicação e Educação (2001-2020)

Publicado originalmente em 1969 pelo Instituto de Capacitación e Investigación en Reforma Agrária, em Santiago de Chile, Extensão ou comunicação? resgata discussões anteriores do autor sobre a relação desigual e equivocada estabelecida entre professores e alunos, comparando-a ao modo hierárquico como agrônomos se relacionavam com camponeses em atividades extensionistas a partir da contraposição entre técnica e prática.

Nele, Freire dedica-se a refletir sobre o conceito de extensão e de comunicação, considerando que ambos são aplicáveis, necessariamente, a uma prática educativa ancorada na formação crítica do sujeito. Sendo assim, busca entender e singularizar cada um desses termos a fim de evitar que uma definição assistencialista assuma o lugar do sentido libertador de nossas práticas educativas.

As citações mais recorrentes referem-se a conceitos como educação bancária, aprendizagem significativa e formação crítica, assim como reflexões sobre interação professor-aluno, diálogo e fundamentos da prática docente. Além disso, também é referência em temas como avaliação de material didático e recurso pedagógico utilizado em sala de aula, salas de informática enquanto método de aprendizagem significativa e atividades dirigidas de formação a distância. Esse grande número de citações justifica-se pelo fato de que o autor foi um dos pensadores que mais aproximou a educação da comunicação, enfatizando sua importância para o processo educativo e designando ao professor o importante papel de mediador do conhecimento.

Considerada uma das produções mais célebres de Paulo Freire, Pedagogia da autonomia: saberes necessários à prática educativa ${ }^{18}$ foi lançada em 1996 - sua última obra publicada em vida. Nela, o autor reflete sobre a prática docente como dimensão social da formação e da transformação do ser humano, elencando valores indispensáveis à prática educativa, tais como a ética crítica, a competência

17. FREIRE, Paulo. Extensão ou comunicação? 8. ed. Rio de Janeiro: Paz e Terra, 1985

18. FREIRE, Paulo. Pedagogia da autonomia. São Paulo: Paze Terra, 2002. 
científica, a solidariedade enquanto compromisso histórico e a amorosidade autêntica, todos ancorados em uma postura politicamente engajada.

Este livro ocupa o segundo lugar dentre os títulos de Paulo Freire mais citados nos artigos científicos produzidos no GP estudado, especialmente em temas que discutem criticamente o progresso científico e tecnológico, que perdem significado por não responderem às necessidades da existência humana. Embasa também as produções ligadas a formação de professores, organização curricular das licenciaturas, formação continuada e prática docente.

Fruto de um generoso gesto intelectual de construção constante do passo a passo de suas reflexões, Freire estabelece neste ensaio três postulados a partir dos quais desenvolve teses, antíteses e sínteses: o primeiro, exposto no capítulo inicial, é o de que não há docência sem discência; o segundo é o de que ensinar não é transferir conhecimento, e o terceiro - apresentado no capítulo final, é o que ensinar é uma especificidade humana.

Ao longo da obra, põe-se a elencar algumas exigências do ato de ensinar: rigorosidade metodológica, pesquisa, respeito aos saberes do educando, criticidade, estética e ética; exige corporificação da palavra pelo exemplo, risco, aceitação do novo e rejeição a qualquer forma de discriminação; exige reflexão crítica sobre a prática, exige o reconhecimento e a assunção da identidade cultural. Discorre também sobre posturas a serem desenvolvidas na formação docente: consciência do inacabamento, o reconhecimento de ser condicionado, respeito à autonomia do ser do educando, humildade, tolerância e luta em defesa dos direitos dos educadores, apreensão da realidade, bom senso, curiosidade, alegria, esperança e a convicção de que a mudança é possível. E ainda trata de discutir e problematizar características essenciais que não podem faltar a educadores: segurança; competência profissional e generosidade; comprometimento; compreensão da educação como forma de intervenção no mundo e de que ensinar exige liberdade e autoridade; tomada consciente de decisões; saber escutar; reconhecer que a educação é ideológica; disponibilidade para o diálogo; e, sobretudo, querer bem aos educandos.

Pedagogia do oprimido ${ }^{19}$ é uma das obras mais conhecidas de Paulo Freire e também uma das mais utilizadas como suporte conceitual e teórico dos artigos de pesquisadores e pesquisadores do GP nos últimos 20 anos, em especial nos estudos que tratam da educação para a cidadania, análise crítica da mídia, processos de aprendizagem, educação para os meios digitais e educação a distância. Escrita em 1968, durante seu exílio no Chile, a obra foi censurada pela ditadura militar e permaneceu inédita no Brasil até 1974. Referência para a chamada pedagogia crítica, o livro discute a relação entre professor e aluno a partir do conceito marxista de luta de classes baseada na exploração, ou seja, classe dominante versus dominada, opressora versus oprimida, colonizadora versus colonizada.

Na reflexão de Freire, a educação tradicional é uma força de conservação e preservação da ordem social e do poder dominante. Nessa lógica, os professores são os dotados de conhecimento, enquanto os alunos, passivos, são meros receptores. Assim, instala-se a relação de hierarquia: professores atuam como 
opressores, doutrinando alunos a aceitarem uma ordem social opressora. Mudar a sociedade, portanto, demanda revolucionar a educação, diz o autor, referindo-se à necessidade de buscar outras formas de educar que considerem os homens e as mulheres como sujeitos de seu tempo histórico, apostando no diálogo humanizado entre educadores e educandos e no exercício prático da liberdade.

Nesta obra, Freire reafirma sua convicção na importância da conscientização para anular a falsa consciência: entender a opressão e buscar formas de superá-la por meio do exercício humano do livre-arbítrio; criar um mundo novo e, nele, uma nova relação social que supere a dominação histórica dos poderosos em relação aos oprimidos. Nesse contexto, cabe aos professores o papel de facilitar a construção do conhecimento, compartilhando problemas e soluções de forma dialógica, crítica e horizontal.

Com primeira edição publicada em 1967, a obra Educação como prática da liberdade $^{20}$ reúne textos que tratam da visão pedagógica e da experiência de Paulo Freire na criação do método de alfabetização de adultos no nordeste brasileiro, pioneiramente na cidade de Angicos, no Rio Grande do Norte, em 1962. Portanto, pouco antes do golpe que destituiu o governo de João Goulart, em 1964, dando início à ditadura civil-militar no Brasil.

Neste ensaio, escrito em 1965, com Freire já no exílio, o educador reflete sobre as marcas políticas vividas pelo seu país e seu povo naqueles anos: a inexperiência democrática, o tratamento ideológico das massas e a exploração humana, assim como o enfrentamento possível e necessário, especialmente em tempos de retrocesso político, para reavivar a chama da luta pela alfabetização da população, tendo o trabalho e a cultura popular como veios potentes de apreensão da consciência, do empoderamento de classe, da autonomia do livre pensar e aprender.

Em registro minucioso, Freire discorre sobre seu método de alfabetização por meio dos círculos de cultura - cuja grande busca inicial era a conscientização do indivíduo como sujeito ativo e capaz de perceber seu tempo histórico. Segundo seus próprios registros, tratava-se de um método ativo, crítico, construído a partir de diálogos e de forma participante a partir de levantamento vocabular da realidade dos educandos, seleção de palavras geradoras, organização de situações cotidianas para contextualizar a experiência e os sentidos, criação de fichas auxiliares para o trabalho dos educadores e, por fim, a construção das fichas de descobertas.

Desenvolvido por Freire durante mais de 15 anos de atuação em comunidades populares, a implementação desse modelo de alfabetização por todo o território nacional, planejada de forma estratégica para a gestão Goulart, foi suspensa e proibida pelo regime militar. Em nossa análise bibliográfica, os artigos que referenciam esta obra de Freire assentam-se em quarto lugar no ranking das mais citadas e tratam de temas ligados a métodos de letramento; experiências em educomunicação; conceitos de educação e cidadania ligados aos direitos humanos; análise sobre o uso das tecnologias sob a perspectiva da educação para as mídias; prática docente e salas de aula como territórios de liberdade.

Publicado no Brasil em 1979, ano em que Paulo Freire retorna ao seu país natal após 15 anos de exílio, Educação e mudança $a^{21}$ também embasa grande parte

20. Idem. Educação como prática da liberdade. Rio de Janeiro: Paz \& Terra, 1967.

21. Idem. Educação e mudança. Rio de Janeiro: Paze Terra, 1982. 
dos papers produzidos pelos pesquisadores deste GP nos últimos 20 anos, especialmente os que se dedicam a discutir escrita e leitura, letramento, autonomia, educação para os meios, e assentam-se em teorias da cultura para discorrer sobre práticas de conhecimento e de liberdade.

Na obra, o autor retoma os estudos sobre sua metodologia de alfabetização de adultos, mas, sobretudo, discute o papel da ciência e da educação no processo de conscientização da sociedade e as mudanças por elas engendradas. Defende a educação como um compromisso social com a transformação da sociedade por meio de ações ativas e solidárias. E que, sob esse manto, o saber pode ser entendido como um ato permanente de superação da ignorância - um trabalho desafiador do homem sobre o mundo por meio de um olhar amoroso, condição para o entendimento de si e do outro. Percorre temas que vão desde o papel docente e o engajamento como ação transformadora até o compromisso dos educadores na luta contra o analfabetismo, a desigualdade e a justiça social. Freire procura demonstrar que, em um mundo de cultura imediatista e mecanicista, a prática pedagógica precisa estar voltada a compreender a sociedade no seu aspecto humano, de forma crítica e libertadora. Nesse sentido, a tarefa que cabe ao educador é ajudar o educando a ativar e exercer essa compreensão crítica do mundo com um olhar ativo e altivo, não acomodado na manutenção das desigualdades.

A importância do ato de ler ${ }^{22}$, obra publicada em 1982, reúne três valiosas contribuições de Freire recuperadas de sua participação em congressos acadêmico-científicos como convidado especial. Nos textos, o autor argumenta que é preciso compreender que aprender a ler e a escrever é, antes de tudo, ser capaz de ler o mundo e seu contexto, vinculando linguagem e realidade, muito além de só ordenar letras e combinar sons. Por ser de temática intrínseca à área da comunicação e da educação, este livro aparece em sexto lugar no ranking das obras mais citadas do autor na pesquisa bibliográfica do GP, embasando especialmente produções ligadas a práticas de alfabetização, alfabetização digital, leitura e letramento, produção de sentidos.

O primeiro texto, "A importância do ato de ler", resulta de alocução por ele proferida na abertura do Congresso Brasileiro de Leitura, na cidade de Campinas, São Paulo, em novembro de 1981. Nele, Freire ensina que linguagem e realidade se prendem dinamicamente, pois compreender um texto através da leitura crítica implica perceber as relações entre texto e contexto, já que a simples memorização mecânica da descrição do objeto não se constitui em conhecimento do objeto. Diz o autor que há uma relação indissociável entre a palavra escrita e a experiência, a realidade. E que a leitura do mundo, que precede sempre a leitura da palavra, implica a continuidade da leitura do mundo - a leitura da "palavramundo". Trata-se, segundo Freire, de movimento dinâmico e um dos aspectos centrais do processo de alfabetização porque, ao engendrar sucessivas leituras críticas, é conscientizador e transformador.

O segundo texto, "Alfabetização de adultos e bibliotecas populares", foi apreato de ler: em três artigos que se complementam. 40. ed. São Paulo: Cortez, 2003

sentado em janeiro de 1982 no XI Congresso Brasileiro de Biblioteconomia Documentação, em João Pessoa, Paraíba. Para Freire, a leitura das palavras e 
sua escrita implicam, necessariamente, a leitura prévia da realidade. Falar de alfabetização de adultos e bibliotecas é falar do problema da leitura e da escrita, que devem ser compreendidos de forma crítica, não ingênua. Conta o autor que todo processo educativo é de natureza política e que a neutralidade é um mito que impera nesse campo e nega a característica política do ato de educar - e aí reside a diferença fundamental entre uma prática ingênua (idealista), uma prática astuta (reacionária) e uma prática crítica (emancipadora). Se na visão crítica o processo educativo é de natureza política, ao educador cabe aclarar e assumir sua posição político-pedagógica e ser coerente na sua prática. Nessa visão crítica, uma biblioteca popular deve ser pensada como um centro cultural e não como um depósito silencioso de livros. Deve estimular seminários de leituras em grupo e a criação de textos a partir do levantamento de história oral recolhida por meio de entrevistas gravadas. Ao citar exemplos de experiências desenvolvidas na Tanzânia, Guiné Bissau e São Tomé e Príncipe, Freire comenta sobre como se organizam as histórias comuns enquanto um acervo vivo da história do grupo.

O terceiro texto, "O povo diz a sua palavra - ou a alfabetização em S. Tomé e Príncipe" foi publicado originalmente em edição especial da Harvard Educational Review, em fevereiro de 1981. Trata de sua experiência como assessor para políticas de alfabetização de adultos na República Democrática de São Tomé e Príncipe, recém instituída após a guerra colonial. Ressalta a não dissociação do seu papel político e de sua prática como assessor. Seu esforço neste projeto de alfabetização foi o de efetivar a relação dinâmica entre a leitura da palavra e a leitura da realidade.

O material de apoio à formação eram os Cadernos de Cultura Popular - não eram cartilhas ou manuais com exercícios e discursos manipulados, mas uma série de textos em linguagem simples para a fase da alfabetização e pós-alfabetização. A série abordou temas de aritmética, saúde, cultura popular etc. com o objetivo de estimular a curiosidade crítica dos educandos e não para leituras mecânicas. A proposta era estimular a participação efetiva do povo enquanto sujeito na reconstrução do país, recém-saído da posição de colônia portuguesa e da condição de um povo sem liberdade, autonomia e autodeterminação política.

\section{CONSIDERAÇÕES FINAIS}

Como forma de comemorar o centenário de nascimento do educador e filósofo Paulo Freire, Patrono da Educação Brasileira e referência estruturante dos estudos educomunicativos no país, este artigo se propôs a localizar, quantificar e qualificar a contribuição do pensamento freiriano na produção acadêmica do Grupo de Pesquisa Comunicação e Educação da Intercom.

De um total de 847 artigos científicos produzidos ao longo das duas últimas décadas pelos pesquisadores nucleados, oriundos de todas as regiões do país, foram localizados 345 artigos que se referiram a Paulo Freire, seja em referências 
bibliográficas, citações diretas e indiretas ou mesmo de forma generalizada utilizando um ou outro conceito do autor, o que estatisticamente corresponde a $41 \%$ da produção do grupo.

Como resultado, a pesquisa aponta que os pesquisadores do GP fazem referência ao educador brasileiro, em especial às obras Extensão ou comunicação?, Pedagogia do oprimido, Pedagogia da autonomia, Educação como prática da liberdade, Educação e mudança e A importância do ato de ler.

Os artigos levantados na pesquisa também utilizam conceitos preconizados pelo autor, como educação bancária, aprendizagem significativa e formação crítica, assim como reflexões sobre interação professor-aluno, diálogo e fundamentos da prática docente. Tal repertório conceitual é notado especialmente nos textos que se dedicam a discutir escrita e leitura, letramento, autonomia, educação para os meios, e assentam-se em teorias da cultura para discorrer sobre práticas de conhecimento e de liberdade, do engajamento como ação transformadora e destacar o compromisso dos educadores na luta contra o analfabetismo, a desigualdade e a justiça social.

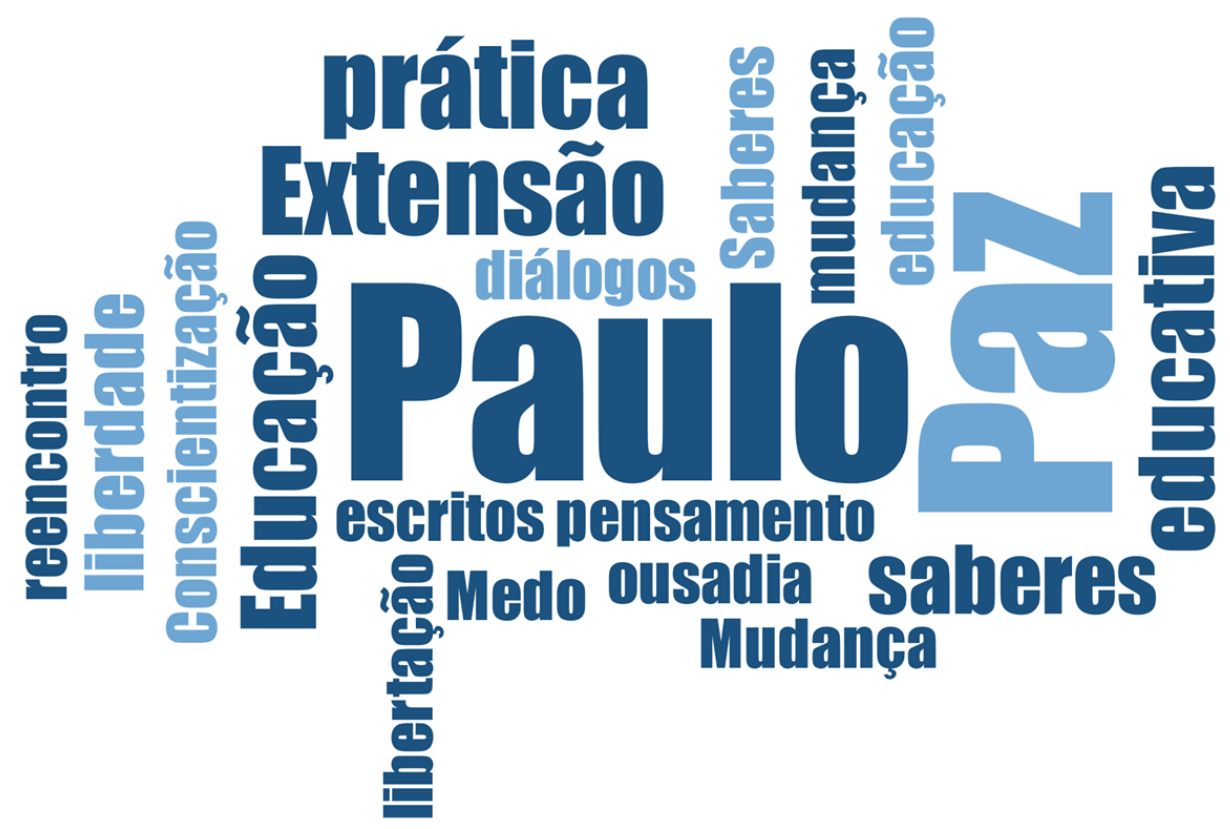

Figura 1: Nuvem de tags das produções acadêmicas do GP Comunicação e Educação com citações a Freire

Como forma de elucidar a influência freireana nos artigos e reflexões do GP, a Figura 1 ilustra sinteticamente os conceitos e contribuições presentes nos textos, estabelecendo conexões diretas com os achados do levantamento realizado nos Anais da Intercom, enfatizando a prática educativa em favor da liberdade, da mudança e na esperança da paz por meio diálogo, da conscientização e dos saberes.

Cientes do papel do educador que se transforma no ato de ensinar e de que a comunicação e a educação estão irmanadas no processo de 
ensino-aprendizagem, entendemos que a reflexão sobre a contribuição freireana é fundamental para a atual situação brasileira, tanto em nível acadêmico quanto político e social. Trazer à tona esses achados, presentes na produção do GP, é um alento na aridez dos tempos atuais, mas fortalece sobretudo a trajetória da pesquisa em Comunicação e Educação, tendo como base a democracia e a emancipação de sujeitos.

Em síntese, as referências a Paulo Freire como um dos fundadores da relação Comunicação e Educação são marcantes nas produções de pesquisadores da área e funcionam como ponto de partida para discussões e investigações futuras mais aprofundadas. Ao buscarmos a raiz do pensamento freiriano, por exemplo, podemos entendê-la como uma grande contribuição para a busca da liberdade de pensar e agir do humano. Baseado na alfabetização enquanto ação concreta de formar cidadãos, o autor defendeu, por toda sua vida, que estudar não é ato mecânico de engolir conteúdos e fórmulas, mas de se transformar em ser consciente de suas possibilidades e autônomo para tomar suas próprias decisões. Deste legado, os pesquisadores do GP Comunicação e Educação também são, mais que nunca, guardiões, pois "o mundo social e humano não existiria como tal se não fosse um mundo de comunicabilidade fora do qual é impossível dar-se o conhecimento humano ${ }^{23}$ "

\section{REFERÊNCIAS BIBLIOGRÁFICAS}

ACCIOLY, Denise Cortez da Silva. Educação para o século XXI: ler e interpretar as mídias dentro da escola. In: CONGRESSO BRASILEIRO DE CIÊNCIAS DA COMUNICAÇÃO, 43., 2020, Salvador. Anais [...]. Salvador: Intercom, 2020.

ANDRADE Rogério Pelizzari de. Da leitura dos media à leitura dos livros: a sala de leitura como espaço de mediação. In: CONGRESSO BRASILEIRO DE CIÊNCIAS DA COMUNICAÇÃO, 35., 2012, Fortaleza. Anais [...]. Fortaleza: Intercom, 2012.

ARAÚJO, Alessandra Oliveira. A rádio-escola como uma experiência de comunicação educativa. In: CONGRESSO BRASILEIRO DE CIÊNCIAS DA COMUNICAÇÃ̃O, 31., 2008, Natal. Anais [...]. Natal: Intercom, 2008.

ASSIS, Leandro Marlon Barbosa; FARBIARZ, Alexandre. Prática docente e as mídias digitais: o cotidiano de uma escola pública na região metropolitana do Rio de Janeiro. In: CONGRESSO BRASILEIRO DE CIÊNCIAS DA COMUNICAÇÃO, 41., 2018, Joinville. Anais [...]. Joinville: Intercom, 2018.

CAMARGO, Cynthia. Sociedade e natureza nas ondas do rádio na Amazônia: representações e significados. In: CONGRESSO BRASILEIRO DE CIÊNCIAS DA COMUNICAÇÃO, 29., 2006, Brasília, DF. Anais [...]. Brasília, DF: Intercom, 2006. 
CITELLI, Adilson. Comunicação e educação: dinâmicas midiáticas e cenários escolares. Ilhéus: Editus, 2021.

CRUZ, Dulce Márcia. Educação a distância por videoconferência: como facilitar a adoção da inovação tecnológica e preparar os professores? In: CONGRESSO BRASILEIRO DE GIÊNCIAS DA COMUNICAÇÃO, 24., 2001, Campo Grande. Anais [...]. Campo Grande: Intercom, 2001.

DELIBERADOR, Luzia Yamashita. A importância da comunicação e do exercício de cidadania para mudar a realidade de uma escola pública. In: CONGRESSO BRASILEIRO DE CIÊNCIAS DA COMUNICAÇÃ̃O, 30., 2007, Santos. Anais [...]. Santos: Intercom, 2007.

FREIRE, Paulo. A importância do ato de ler: em três artigos que se complementam. 40. ed. São Paulo: Cortez, 2003.

FREIRE, Paulo. Educação como prática da liberdade. Rio de Janeiro: Paz \& Terra, 1967.

FREIRE, Paulo. Educação e mudança. Rio de Janeiro: Paz e Terra, 1982.

FREIRE, Paulo. Extensão ou comunicação? 8. ed. Rio de Janeiro: Paz e Terra, 1985.

FREIRE, Paulo. Pedagogia da autonomia. São Paulo: Paz e Terra, 2002.

FREIRE, Paulo. Pedagogia da Autonomia: saberes necessários à prática educativa. 25. ed. São Paulo: Paz e Terra, 2002.

FREIRE, Paulo. Pedagogia do oprimido. 45. ed. São Paulo: Paz e Terra, 2010.

GAIA, Rossana Viana. Notícias na escola: possibilidades de leituras críticas. In: CONGRESSO BRASILEIRO DE CIÊNCIAS DA COMUNICAÇÃO, 25., 2002, Salvador. Anais [...]. Salvador: Intercom, 2002.

GOMES, Ana Luisa Zaniboni; NAGAMINI, Eliana; PINHEIRO, Rose Mara. Grupo de Pesquisa Comunicação e Educação da Intercom: quem somos, onde estamos, o que estudamos e quais horizontes nos desafiam. In: CONGRESSO BRASILEIRO DE CIÊNCIAS DA COMUNICAÇÃO, 41., 2018, Joinville. Anais [...]. Joinville: Intercom, 2018.

TOMITA, Iris; DALLA COSTA, Rosa Maria. A interface comunicação e educação em congressos científicos: diferenças e aproximações. In: CONGRESSO BRASILEIRO DE CIÊNCIAS DA COMUNICAÇÃO, 34., 2011, Recife. Anais [...]. Recife: Intercom, 2011.

TOSTA, Sandra Pereira. Tecnologias digitais na educação: estudo de caso em escolas da rede pública em Minas Gerais. In: CONGRESSO BRASILEIRO DE CIÊNCIAS DA COMUNICAÇÃO, 25., 2002, Salvador. Anais [...]. Salvador: Intercom, 2002. 